

\title{
Pengaruh Kepribadian Hardiness terhadap Turnover Intention
}

\author{
Muhammad Hafiz Chiesa A \\ Jurusan Psikologi, Universitas Negeri Yogyakarta; Jl. Colombo No. 1 Sleman Yogyakarta, 55281 \\ chiesa.hafiz@yahoo.com
}

\begin{abstract}
Abstrak
Berdasarkan survei awal yang dilakukan oleh peneliti, ditemukan bahwa turnover intention dapat terjadi karena rendahnya tingkat hardiness pada karyawan. Oleh sebab itu, penelitian ini bertujuan untuk mengetahui pengaruh kepribadian hardiness terhadap turnover intention pada karyawan. Penelitian ini menggunakan pendekatan kuantitatif dengan jenis penelitian ex-post facto. Penelitian ini dilakukan di CV. Yuasa Food Berkah Makmur Wonosobo. Subjek penelitian ini adalah seluruh karyawan CV. Yuasa Food Berkah Makmur berjumlah 50 orang dan yang mengembalikan instrument berjumlah 35. Instrumen pengumpulan data berupa skala turnover intention dan skala hardiness. Validitas instrumen tersebut diuji menggunakan expert judgement dan analisis butir sedangkan reliabilitas instrumen diukur dengan menggunakan rumus $A \not p h a$ Cronbach. Hasil pengukuran reliabilitas pada variabel turnover intention yaitu sebesar 0,880 dan pada variabel hardiness yaitu 0,882. Analisis data menggunakan uji regresi sederhana. Berdasarkan hasil analisis regresi sederhana, ditemukan bahwa bardiness berpengaruh terhadap turnover intention dengan nilai $\mathrm{r}=0,316$ dan $\mathrm{R}_{2}=10 \%$ yang berarti masih terdapat $90 \%$ dipengaruhi oleh faktor-faktor lain. Oleh sebab itu dapat disimpulkan bahwa kepribadian hardiness mempengaruhi turnover intention.
\end{abstract}

Kata Kunci: kepribadian hardiness, turnover intention, hardiness

\begin{abstract}
Based on an initial survey conducted by researcher, it was found that turnover intention can occur due to low level of employee's hardiness. Therefore, this study aim to determine the effect of hardiness personality toward employee's turnover intention. This Study uses a quantitative approach to the type of ex-post facto research. This research was conducted at CV. Yuasa Food Berkah Makmur with subjects all of 50 employees but only 35 employees returned the instrument. The research instrument used in this research was a scale of turnover intention and scale of hardiness. The instrument;s validity was tested using expert judgement and item analysis while the instrument's reliability was measured using the Cronbach Alpha formula. The result of reliability measurement on the variable turnover intention is 0.880 and on the variable hardiness is 0.882 . data analysis uses a simple regression test. Based on the results of a simple regression analysis, it was found that hardiness influences turnover intention with a value of $\mathrm{r}=0.316$ an $\mathrm{R}_{2}=10 \%$ which means that are still $90 \%$ influenced by other factors. Therefore it can be concluded that hardiness personality influences turnover intention.
\end{abstract}

Keywords: hardiness personality, turnover intention, hardiness

\section{Pendahuluan}

Sumber daya manusia (SDM) merupakan salah satu faktor yang sangat penting bagi sebuah organisasi ataupun perusahaan, baik dalam perusahaan skala kecil maupun dalam skala besar. Sumber daya manusia dapat dikatakan sumber untuk menggerakkan, mengarahkan dan mempertahankan suatu organisasi dalam tuntutan perkembangan zaman. Tanpa adanya sumber daya manusia yang mumpuni sebuah organisasi tidak akan berkembang dengan baik.

Cara untuk mendapatkan sumber daya manusia yang berkualitas tidak hanya dilakukan dengan perekrutan namun dapat 
dilakukan dengan pengelolaan sumber daya manusia dalam perusahaan tersebut. Perusahaan yang dapat mengelola sumber daya manusianya akan meningkatkan keberhasilan dalam mewujudkan visi misi perusahaan tersebut. Perusahaan yang ingin berkembang dengan cepat membutuhkan sumber daya manusia yang berkualitas. Sumber daya manusia yang ideal menurut Al-Qeed (2016) adalah performa dan pencapaian yang melibatkan produktivitas, keakuratan, prestasi yang melebihi harapan dan menggunakan kemampuan (skill) dan teknik yang modern untuk menyelesaikan pekerjaannya. Menurut Wijono (2010), sumber daya manusia yang berkualitas merupakan salah satu faktor penentu agar perusahaan dapat bekerja efektif dan maksimal untuk dapat bersaing di pasar global.

Dewasa ini, ketatnya persaingan dalam dunia kerja menimbulkan berbagai masalah di perusahaan. Salah satu masalah yang tidak lepas dari perusahaan dan sumber daya manusianya adalah turnover. Spector (2006) mengartikan turnover sebagai keluarnya karyawan. Menurut Robbins dan Judge (2009), turnover adalah tindakan pengunduran diri secara permanen yang dilakukan oleh karyawan, baik secara sukarela ataupun tidak secara sukarela. Banyak faktor yang dapat menyebabkan turnover pada seorang karyawan, antara lain adalah menurunnya ketertarikan terhadap pekerjaan yang sedang dijalani, tawaran pekerjaan yang lebih baik dari segi lingkungan, ketertarikan, gaji, dan dapat juga karena PHK yang diberikan oleh perusahaan yang menyebabkan mau tidak mau karyawan tersebut harus keluar dari pekerjaannya.

Turnover mempunyai dampak yang signifikan bagi sebuah perusahaan. Salah satu dampak yang didapat oleh perusahaan adalah pada sektor finansial, seperti menurunkan tingkat produksi dan juga menambah biaya yang dikeluarkan perusahaan untuk perekrutan, penyeleksian, dan pelatihan bagi karyawan baru. Turnover yang dilakukan oleh seorang karyawan sering terjadi pada karyawan yang mengalami stress kerja.

Turnover merupakan hal yang biasa terjadi di dalam perusahaan, namun akan menjadi berbahaya apabila tingkat dari turnover itu tinggi. Perusahaan yang ingin mencapai visi dan misinya seharusnya menghindari turnover seminimal mungkin agar tujuan dari perusahaan dapat tercapai. Sektor industri di Amerika Serikat mengalami kerugian sekitar $\$ 20.000$ untuk menggaji karyawan dan menggantinya dengan karyawan baru. Survei yang dilakukan oleh Mercer Indonesia menyebutkan rata-rata jumlah karyawan di Indonesia yang pindah pada tahun 2018 sebesar 7,4\%. Sebesar 53\% responden Mercer Indonesia beralasan berpindah pekerjaan karena kurangnya kesempatan berkarir dan berkembang; 51\% respon karena merasa gaji yang didapatkan kurang kompetitif; $17 \%$ responden beralasan karena hubungan yang kurang harmonis dengan sesama karyawan atau atasannya; 15\% responden memilih keluar karena jarak waktu tempuh berangkat bekerja yang lama; 14\% responden berasalan karena pekerjaan yang tidak cocok; 10\% responden beralasan karena kultur perusahaan yang tidak cocok; dan 5\% responden karena waktu lembur yang tidak fleksibel.

Sebelum melakukan turnover, seorang karyawan biasanya memiliki niat atau intensi terlebih dahulu. Chaplin (2006) menyatakan bahwa intensi adalah suatu perjuangan guna mencapai satu tujuan. Niat untuk keluar dari pekerjaanya disebut turnover intention. Turnover intention tersebut disebabkan karena karyawan kurang mendapat perhatian atau penghargaan dari perusahaan dan kebutuhannya tidak tercukupi. Karyawan yang memiliki turnover intention kemungkinan akan menurunkan produktivitas dalam pekerjaannya. Hal tersebut dapat terjadi karena karyawan 
tersebut mengalami penurunan ketertarikan pada pekerjaannya.

Menurut Mobley dalam Nisa (2012), turnover intention dapat terjadi dikarenakan dua faktor yaitu eksternal dan internal. Faktor eksternal meliputi faktor kategori jabatan, besar kecilnya organisasi, besar kecilnya unit kerja, upah dan bobot kerja. Kemudian, faktor internal yang merupakan faktor yang berasal dari karakteristik personal karyawan seperti usia, stres, masa kerja, jenis kelamin, pendidikan, data biografik, kepribadian, minat bakat dan kemampuan.

Namun, tidak semua karyawan selalu memiliki turnover intention. Hal tersebut dikarenakan setiap karyawan memiliki tipe kepribadian yang berbedabeda dalam menghadapi masalah. Masalah pekerjaan yang menumpuk dapat menyebabkan stres yang berujung pada munculnya turnover intention. Kepribadian menurut Allport (dalam Chaplin, 2006) adalah suatu organisasi yang dinamis dari sistem psikofisis individu yang menentukan tingkah laku dan pemikiran individu secara khas.

Cooper (2001) menyebutkan ada beberapa variabel kepribadian yang mampu berpengaruh terhadap stres. Kobassa dan Maddi (1982) menyatakan tipe kepribadian yang mempunyai kemampuan dan daya tahan dalam menghadapi masalah-masalah yang datang adalah hardiness. Ada beberapa individu yang mempunyai hardiness yang tinggi terhadap berbagai masalah dalam perusahaan namun ada juga yang memiliki hardniness yang rendah sehingga rentan memiliki kecenderungan untuk keluar dari perusahaan karena seringnya berhadapan dengan situasi yang menegangkan.

Kobassa dan Maddi (1982) menyatakan bahwa hardiness merupakan karakteristik kepribadian yang dapat membantu untuk melindungi diri dari pengaruh negatif stres. Kobassa (1982) berpendapat bahwa individu yang memiliki tipe kepribadian hardiness memiliki beberapa cara untuk menghadapi masalahmasalah pekerjaan. Kepribadian hardiness dapat dikatakan penting dimiliki oleh setiap individu termasuk karyawan, karena setiap pekerjaan akan memberikan tantangan tersendiri yang akan membuat karyawan lebih berkembang karena karyawan yang memiliki kepribadian hardiness akan lebih bersemangat dalam melakukan tugastugasnya. Akan tetapi, tidak semua karyawan memiliki kepribadian hardiness yang baik. Apabila seorang karyawan memiliki kepribadian hardiness yang buruk, maka akan dengan mudahnya karyawan tersebut terkena stres ketika dihadapkan dengan masalahmasalah dalam pekerjaannya yang menyebabkan timbulnya turnover intention.

Penelitian ini dilakukan di CV. Yuasa Food Berkah Makmur yang merupakan perusahaan yang bergerak di bidang pengolahan pangan. Berdasarkan wawancara sederhana dengan beberapa karyawan di perusahaan CV. Yuasa Food Berkah Makmur didapatkan data bahwa ada beberapa karyawan memiliki keinginan untuk keluar dari perusahaan. Alasannya karena sebagian merasa pekerjaan mereka membosankan dan monoton karena selalu berada di dalam ruangan. Selain itu beberapa karyawan juga mengatakan bahwa mereka terkadang tidak dapat mengatasi permasalahan pekerjaan sehingga mengakibatkan stres. Selanjutnya, didapati hasil bahwa perusahaan jarang melakukan perekrutan baru sehingga dapat dikatakan pergantian karyawan pada CV. Yuasa Food Berkah Makmur berlangsung secara lambat. Berdasarkan hasil wawancara tersebut dimungkinkan karena sebagian karyawan yang diwawancarai kurang memiliki kepribadian hardiness.

Setiap karyawan pasti menemui permasalahan dalam pekerjaannya. Permasalahan pekerjaan dapat muncul karena tuntutan dan tantangan yang diberikan oleh pekerjaan, sehingga dapat menyebabkan stres bagi karyawan. Tingkat 
stres yang tinggi dapat memunculkan turnover intention. Hal tersebut selaras dengan penelitian sebelumnya yang dilakukan oleh Dewi dan Wibawa (2016) yang menunjukkan bahwa semakin meningkatnya stres, maka semakin tinggi juga tingkat turnover intention yang dimiliki.

Salah satu faktor yang dapat memengaruhi turnover intention adalah kepribadian, khususnya kepribadian hardiness. Seorang karyawan yang memiliki kepribadian hardiness melihat suatu permasalahan sebagai tantangan dan yakin dapat menyelesaikannya sehingga permasalahan tersebut tidak akan menghambat pekerjaannya. Hal tersebut selaras dengan penelitian yang dilakukan oleh Dodik dan Astuti (2017), yang mengatakan bahwa semakin tinggi kepribadian hardiness maka semakin rendahnya stres kerja yang dimiliki. Berdasarkan penjelasan tersebut dapat disimpulkan bahwa kepribadian hardiness secara tidak langsung dapat memengaruhi munculnya turnover intention.

Penelitian ini memfokuskan pada pengaruh hardiness terhadap turnover intention. Penelitian ini menarik untuk dilakukan mengingat penelitian dengan topik serupa masih langka di Indonesia. Hal menarik lainnya adalah dengan banyaknya tipe pekerjaan yang ada di Indonesia memungkinkan semakin bervariasinya pengaruh hardiness terhadap turnover intenion.

\section{Metode Penelitian}

Penelitian ini merupakan penelitian ex post facto dengan pendekatan kuantitatif. Sementara pendekatan yang digunakan pada penelitian ini yaitu pendekatan kuantitatif yang didefinisikan oleh Sugiyono (2017: 14) sebagai metode penelitian yang berlandaskan pada filsafat positivisme, digunakan untuk meneliti pada populasi atau sampel tertentu, teknik pengambilan sampel pada umumnya dilakukan secara random, pengumpulan data menggunakan instrumen penelitian, analisis data bersifat kuantitatif/statistik dengan tujuan untuk menguji hipotesis yang telah ditetapkan.

Penelitian ini dilaksanakan di perusahaan pembuatan Carica Yuasa Food di Wonosobo. Penelitian dilaksanakan pada bulan Oktober 2019.

Populasi penelitian merupakan kelompok subjek yang akan dikenai generalisasi hasil penelitian yang dilakukan. Kelompok subjek dapat dikatakan sebagai populasi apabila memiliki karakteristik tertentu yang dapat membedakan dengan kelompok subjek lainnya (Azwar, 2018:109). Karakteristik subjek pada penelitian ini adalah karyawan pada perusahaan Yuasa Food di Wonosobo. Populasi pada penelitian ini berjumlah 50 orang dan yang mengembalikan data berjumlah 35 orang.

Penelitian ini menggunakan skala psikologi sebagai alat ukurnya. Menurut Azwar (2018:6) karakteristik skala psikologi biasanya digunakan untuk mengukur atribut nonkognitif, aitemnya berupa pernyataan atau pertanyaan yang menunjukkan perilaku dan aitem tidak bisa dikategorikan menjadi jawaban benar atau salah. Instrumen pada penelitian ini menggunakan skala sikap model Likert. Skala sikap model Likert pada penelitian ini dibuat berdasarkan kisi-kisi yang mengacu pada indikator keperilakuan dari setiap variabel. Penelitian ini menggunakan skala psikologis dengan skala sikap model Likert yang dimodifikasi menjadi empat alternatif jawaban pada setiap variabel.

Analisis data pada penelitian ini meliputi uji hipotesis. Selain itu analisis data dalam penelitian ini menggunakan regresi linier sederhana dengan bantuan program computer SPSS 16 untuk menjawab hipotesis dan mengetahui predictor X terhadap Y.

\section{Hasil Penelitian}


Analisis deskriptif digunakan untuk mengubah data ordinal menjadi data interval dengan perhitungan manual yang berdasarkan atas norma kategorisasi (Azwar, 2018).

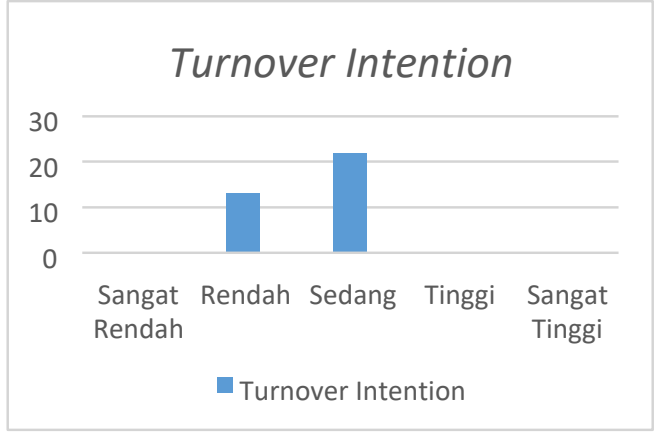

Gambar 1. Diagram Turnover Intention

Berdasarkan Gambar 1, dapat di ketahui frekuensi paling banyak berada pada kategori sedang, yaitu sejumlah 22 karyawan.

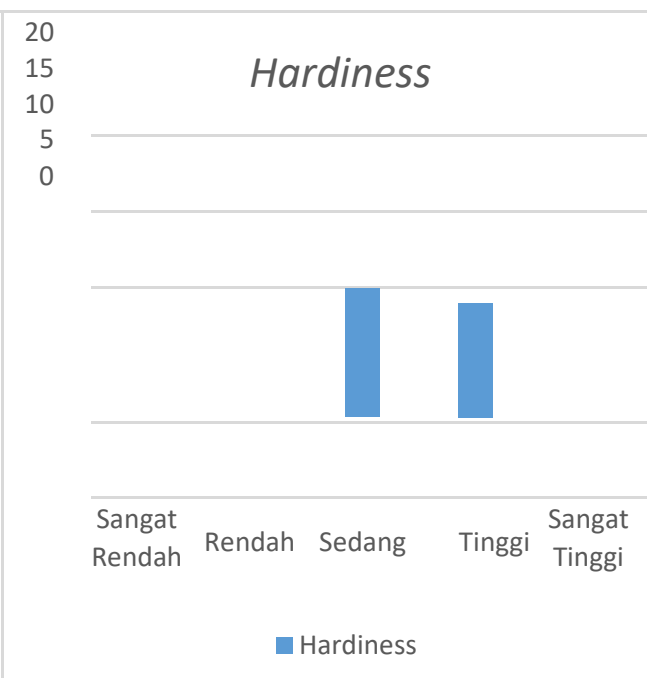

Gambar 2. Diagram Turnover Intention

Berdasarkan Gambar 2. Dapat diketahui frekuensi paling banyak berada pada kategori sedang yaitu berjumlah 18 karyawan.

\section{Pembahasan}

Penelitian ini dilakukan pada 35 karyawan CV Yuasa Food Berkah Makmur yang didominasi oleh karyawan perempuan sebanyak 24 orang. Rata-rata karyawan penelitian ini berusia 46-50 tahun. Karyawan pada perusahaan ini rata-rata bekerja selama 6-10 tahun. Secara umum kriteria di perusahaan ini merupakan karyawan generasi $\mathrm{X}$ dengan masa kerja yang relatif lama atau lebih dari 5 tahun.

Selanjutnya berdasarkan hasil analisis deskriptif variabel turnover intention, diketahui bahwa rata-rata tingkat turnover intention berada dalam kondisi sedang ke rendah dengan perbandingan sedang 22 responden $(62,9 \%)$ dan rendah sebanyak $13(37,1 \%)$ responden. Hal tersebut sesuai dengan penjelasan sebelumnya, yang mana rata-rata lama bekerja karyawan pada perusahaan ini lebih dari 5 tahun. Hal tersebut sejalan dengan pendapat yang dikemukakan oleh Mobley (1986), faktor yang dapat memengaruhi turnover intention adalah usia dan masa kerja. Mobley (1986) mengungkapkan bahwa karyawan yang lebih muda memiliki tingkat turnover intention yang cenderung tinggi dan sebaliknya karyawan yang lebih tua memiliki tingkat turnover intention yang lebih rendah. Hal tersebut disebabkan karyawan yang lebih tua enggan untuk berpindah-pindah tempat kerja karena berbagai alasan seperti keluarga, mobilitas menurun, tidak mau repot, dan karena energi yang sudah berkurang.

Berdasarkan hasil analisis deskriptif, diketahui bahwa rata-rata tingkat hardiness karyawan berada pada tingkat sedang ke tinggi dengan perbandingan sedang 18 responden dan tinggi 16 responden. Dari hasil tersebut mayoritas usia subjek lebih dari 45 tahun. Selaras dengan penelitian yang dilakukan oleh Sandhu (2009) dalam penelitiannya menemukan bahwa subjek dengan usia $>45$ tahun memiliki kepribadian hardiness yang lebih tinggi, semakin bertambahnya usia semakin memiliki komitmen dan kontrol yang kuat begitu juga dengan bertambahnya usia subjek semakin mudah untuk menerima perubahan. Namun, hasil dari penelitian ini tidak dapat 
digeneralisasikan pada seluruh karyawan CV. Yuasa Food Berkah Makmur karena rentang usia subjek terpaut terlalu jauh yang artinya karyawan yang berusia lebih muda tidak dapat disamakan dengan karyawan yang berusia lebih tua.

Setelah melakukan kategorisasi tingkat hardiness dan tingkat turnover intention pada karyawan, peneliti melakukan uji prasyarat analisis dan uji hipotesis. Berdasarkan uji hipotesis, diketahui bahwa hasil koefisien determinasi (R2) sebesar 0,100. Hal tersebut menunjukan besarnya kontribusi hardiness dalam memengaruhi turnover intention adalah sebesar $10 \%$, sisanya $90 \%$ dipengaruhi oleh variabel lain. Variabel lain yang dapat memengaruhi turnover intention salah satunya dapat berupa stres kerja. Penelitian yang dilakukan oleh Dewi dan Wibawa (2016) mendapati hasil bahwa stres kerja memiliki pengaruh langsung secara positif dan signifikan pada turnover intention pada karyawan. Artinya semakin tinggi stres yang dialami karyawan akan meningkatnya tingkat turnover intention.

Hasil penelitian ini diperkuat dengan hasil penelitian yang dilakukan oleh Ellyza (2008) pada 70 karyawan AJB Bumiputera 1912 wilayah Semarang dengan karakteristik karyawan yang berstatus kontrak dan masa kerja di bawah 5 tahun mendapati hasil bahwa korelasi antara hardiness dan turnover intention bersifat negatif.

Hasil penelitian ini juga sejalan dengan hasil penelitian yang dilkakukan oleh Ridwan dan Retno (2013) dengan subjek sebanyak 66 orang karyawan. Penelitian tersebut menghasilkan kesimpulan bahwa terdapat hubungan negatif yang signifikan antara hardiness dengan turnover intention pada karyawan.

Hal yang membedakan penelitian ini dengan dua penelitian tersebut adalah terletak pada responden. Pada penelitian ini, rata-rata responden berusia lebih dari 46-50 tahun, telah bekerja selama lebih dari 5 tahun dan berstatus karyawan tetap pada perusahaan CV. Yuasa Food Berkah Makmur.

Hasil penelitian ini membuktikan bahwa hardiness berpengaruh terhadap turnover intention pada karayawan CV. Yuasa Food Berkah Makmur. Hardiness yang relatif sedang ke tinggi yang dimiliki oleh para karyawan dapat berpengaruh pada rendahnya turnover intention pada karyawan. Tingkat hardiness yang tinggi pada karyawan CV. Yuasa Food Berkah Makmur dapat menghambat tingkat turnover intention. Alasan mengapa kepribadian hardiness dapat menghambat turnover intention adalah karena karyawan yang memiliki hardiness yang tinggi dapat mengurangi dampak dari permasalahanpermasalahan yang ditemui saat bekerja. Selain itu karyawan yang memiliki kepribadian hardiness akan memandang suatu masalah sebagai batu loncatan atau tantangan dan percaya bahwa dirinya dapat mengendalikan permasalahan tersebut. Hal tersebut selaras dengan pernyataan dari Nurtjahjanti (2011) bahwa hardiness merupakan karakteristik yang dapat mengendalikan kejadian-kejadian yang tidak menyenangkan dan dapat memberikan makna positif terhadap kejadian tersebut sehingga tidak menimbulkan stres pada individu. Kemampuan untuk mengendalikan kejadian-kejadian yang tidak menyenangkan tersebut dapat membantu individu untuk mempunyai karir yang sukses. Penjelasan tersebut didukung oleh penelitian yang dilakukan oleh Law (2005) tentang komitmen organisasi interactive dan hardiness pada turnover intention akuntan publik di Amerika Serikat menyatakan bahwa hardiness dapat menjadi sesuatu yang penting bagi individu untuk membangun sebuah perjalanan karir yang sukses.

Terbuktinya hipotesis dalam penelitian ini dapat memberikan informasi bahwa hardiness dapat menjadi prediktor turnover intention pada karyawan. Oleh karena itu, hardiness yang tinggi perlu 
dimiliki oleh karyawan agar turnover intention pada karyawan menurun.

\section{Simpulan dan Saran}

Kepribadian hardiness terbukti memiliki pengaruh terhadap turnover intention pada karyawan CV. Yuasa Food Berkah Makmur dengan hasil analisis regresi yang telah dilakukan, yang menunjukan nilai $r=$ dan $R 2=0,100$ atau $10 \%$. Hal ini berarti kepribadian hardiness dapat menjadi prediktor turnover intention.

Bagi pihak perusahaan, perlu meningkatkan kepribadian hardiness agar niat atau keinginan yang dimiliki karyawan untuk keluar dari perusahaan menurun. Untuk meningkatkan tingkat hardiness perusahaan dapat mengadakan lebih banyak kegiatan dan pelatihan yang sekiranya dapat memunculkan, meningkatkan dan mempertahankan hardiness para karyawan dalam menjalani pekerjaan agar tingkat turnover intention dapat menurun.

Hasil dari penelitian ini dapat menjadi bahan evaluasi diri. Dalam penelitian ini ditemukan fakta bahwa tingkat turnover intention berada pada kategori sedang ke rendah. Oleh karena itu, karyawan diharapkan dapat meningkatkan kepribadian hardiness sehingga tingkat turnover intention dapat berkurang.

Bagi peneliti selanjutnya, dapat mengaplikasikan variabel independen lain untuk melihat bagaimana pengaruhnya dengan variabel turnover intention, karena dalam penelitian ini besarnya pengaruh yang didapat tidak terlalu tinggi. Selain itu, peneliti selanjutnya diharapkan dapat meminimalkan bias yang terjadi karena kurangnya interaksi terhadap subjek. Cara yang dapat dilakukan yaitu memberikan angket atau skala psikologis sebelum memulai pekerjaan serta mendampingi subjek saat mengisi skala psikologis.

Daftar Pustaka
Al-Qeed, Marzouq A., dkk. (2016). The Impact of Ideal Employee Award on the Retention of Distinctive Competence in Public Sector

Organizations in the Hashemite Kingdom of Jordan: A Field Study if Public Sector Employees Who Obtained the Ideal Employee. International Joumal of Business and Social Science. Vol. 7, No. 3.

Azwar, S. (2018). Metode Penelitian Psikologi (Edisi 2). Yogyakarta: Pustaka Pelajar.

(2018). Penyusunan Skala Psikologi (Edisi 2). Yogyakarta: Pustaka Pelajar.

(2018). Reliabilitas dan Validitas (Edisi 4). Yogyakarta: Pustaka Pelajar.

Bart, Smet. (1994). Psikologi Kesehatan. Jakarta: PT. Gramedia Widiasarna Indonesia.

Chaplin, J.P. (2006). Kamus Lengkap Psikologi (Kartini Kartono, Trans.). Jakarta: PT. Raja Grafindo Persada.

Dewi, Ayu B.P. \& Wibawa, I Made A.W. (2016). Pengaruh Stres Kerja Pada Turnover Intention yang Dimediasi Kepuasan Kerja Agen AJB Bumiputera 1912. E-jurnal Manajemen Unud, Vol. 5 No.6, 2016:3560-3588.

Dodik, A.A. \& Astuti K. (2017). Hubungan Antara Kepribadian Hardiness dengan Stres Kerja pada Anggota Polri Bagian Operasional di Polresta Yogyakarta. INSIGHT Vol. 10, No. 1, Februari 2012.

Ellyza, M. U. Harlina N. Prasetyo B. W.

(2008). Hubungan Antara 
Hardiness Dengan Intensi Turnover Pada Agen Produksi Asuransi Jiwa (AJB) Bumiputera 1912 di Wilayah Asper Semarang. Skripsi. Fakultas Psikologi Universitas Diponegoro.

Evendi, Ridwan. Retno, D. (2013). Hubungan Antara Hardiness (Kepribadian Tahan Banting) Dengan Intensi Turnover pada Karyawan PT Sumber Alfaria Trijaya Tbk di Wilayang Gombong Kabupaten Kebumen. PSYCHO IDE $A$ Tahun 11 No. 2, Juli 2013.

Florian, V., Mikulincer, M., \& Taubman, O. (1995). Does Hardiness Contribute to Mental Health During A Stressful Real-Life Situatuin? The Role of Appraisal Coping. Journal of Personality and Social Psychology. Doi: 1995-25080-001

Harnoto. (2002). Manajemen Sumber Daya Manusia. Edisi Kedua. Jakarta: PT. Prehalindo.

Hutomo, I.S. (2014). Kepribadian Tangguh (Hardiness) Pada Guru Sekolah Luar Biasa B dan C. Skripsi. Program Sarjana Psikologi, Fakultas Psikologi Universitas Muhammdiyah Surakarta.

Kobassa, S.C., Maddi, S.R., Kahn, S. (1982). Hardiness and Health: A Prospective Study. Journal of Personality and Social Psychology. 42 (1). 168-177.

Law, D. W. (2005). Interactive Organizational Commitment and Hardiness in Public Accountant' Turnover. Managerial Auditing Journal, 20,4, 383-393.

Maddi, S. R. (2002). The Story of Hardiness: twenty Years of
Theorizing, Research, and Practice. Consulting Psychology Journal: Practice and Research, Vol. 54, No. 3.

Mobley, W. H. (1986). Pergantian Karyawan: Sebab, Akibat dan Pengendaliannya. Terjemahan Nurul Iman. Jakarta: PT Pustaka Binaman Pressindo.

Mobley, W.H. (1977). Intermediate Linkages in the Relationship Between Job Satisfaction and Employee Turnover. Journal of Applied Psychology, Vol. 62, No. 2, 237-240.

Nisa, H. D. W., dkk. (2012). Hubungan Antara Iklim Organisasi Dengan Intentsi Turnover Pada karyawan. Jurnal Semnas, Malang: Universitas Muhammadiyah.

Nugroho, Edy \& Santoso Anwar. (2015). Pengaruh Kepuasan Kerja dan Stres Kerja terhadap Turnover Intention (Studi Kasus pada PT. Istana Kebayoran Raya Motor Cabang Pondok Indah), Jurnal Manajemen, Vol. 1 No. 2.

Nurtjahjanti, H., \& Ratnaningsih, I. Z. (2011). Hubungan Kepribadian Hardiness dengan Optimise pada Calon Tenaga Kerja Indonesia (CTKI) Wanita di BLKLN Disnakertrans Jawa Tengah. Jurnal Psikologi Undip. 10, No. 2., 126132.

Porter. L. W., R. M. Steers, R. T. Mowday, dan P. V. Boulian. (1974). Organizational Commitment, Job Satisfaction, adn Turnover Among Psyatric tehnicians. Journal of Applied Psychology,59. Pp. 603-609.

Robbins, Stephen P. \& Timothy A. Judge. (2009). Organizational Behavior. 13 Three Edition, USA: Pearson International Edition, PrenticeHall. 
Ronald Sukwadim, Milkha Meliana. (2014).

Faktor-Faktor yang Mempengaruhi Kinerja dan Turnover Intention Karyawan Usaha Kecil Menengah, Jurnal Rekayasa Sistem Industri, Vol. 3., No. 1. Sandhu, K. S. (2009). Personality Hardiness of Indian Coaches In Relation to their age and coaching experience. A journal of Exercise Sciece and Physiotherapy, 5(1), 38-41.

Santrock, J.W (2015). Adolescence. Perkembangan Remaja. Jakarta: Erlangga.

Sarafino, E.P. (1998). Health Psychology : Biopsychosocial Interactions. Third Edition. United State of American: John Wiley \& Sonc, Inc.

Sari, Rindi Nurlaila. (2014). Pengaruh Kepuasa Kerja, Stres Kerja dan Komitmen Organisasi Terhadap Turnover Intention (Pada Hotel Ibis Yogyakarta). (Skripsi) Fakultas Ekonomi Universitas Negeri Yogyakarta.

Spector, P.E. (2006). Industry and Organizational Psychology. USA: John Willey and Sons,Inc.

Sugiyono. (2017). Metode Penelitian Pendidikan (pendekatan kuantitatif, kulaitatif, dan red). Bandung Alfabeta.

Sukardi. (2011). Metodologi Penelitian Pendidikan. Jakarta: PT Bumi Aksara.

Wijono, Sutarto. (2010). Psikologi Industri dan Organisasi. Jakarta: Fajar Interpratama Offset. 